\title{
Life Cycle Assessment of Mobile Telephone Networks, with Focus on the End-of-Life Phase
}

\author{
Wolfram Scharnhorst \\ Swiss Federal Laboratories for Materials Testing and Research, Überlandstrasse 129, 8600 Dübendorf, Switzerland \\ (Wolfram.Scharnhorst@empa.ch)
}

\section{DOI: http://dx.doi.org/10.1065/lca2006.05.247}

Having its first practical applications in the 1920s, today, after the commercial successful breakthrough of the Global System for Mobile communication standard (GSM $\left.{ }^{1}\right)$ and the upcoming Universal Mobile Telecommunication System (UMTS ${ }^{2}$ ) standard, mobile telephony has become an indispensable service in almost everybody's life. The numbers of mobile phone networks launched as of the mobile phones sold per year rise and continue to rise drastically (GSMAssociation 2005). This tremendous growth however, is associated with a distinctively increasing amount of communication equipment, e.g. mobile phones, server racks, etc., that needs to be processed as it reaches the end of its useful service life. Due to its marginality in terms of mass and physical distribution environmentally sound End-of-Life (EoL) treatment of electronic scrap from mobile phone networks was not an issue in the beginning of commercial mobile telephony. However, the increasing amount of mobile phone network equipment and the still decreasing life cycles of various components, e.g. mobile phones, contributing on the one hand to a depletion of partially extremely rare resources and on the other hand deemed to cause hazardous environmental effects due to e.g. emissions of heavy metals requires the development of environmentally sparing network components that also meet the governmental regulations such as the WEEE and RoHS (CEC 2003a, CEC 2003b). In order to analyse and, based on the interpretations of the analyses, improve the environmental performance of electronic components life cycle assessment (LCA) has been increasingly recognised as a powerful tool (Malmodin et al. 2001, Nokia 2004) able to give an impression on the potential environmental consequences associated with such products. However, LCA on such complex products, actually product systems (Joerges 1988), like mobile phone networks, typically suffer from the following limitations:

- Omission of the EoL phase.

- Improper life cycle modelling (with respect to the valid technical standards).

- Insufficient or missing life cycle inventory data on mobile telephone networks.

- Poor stakeholder involvement and result communication.

${ }_{1}^{1}$ Mobile phone networks complying with the GSM standard belong to the second generation (2G) of mobile phone networks.

2 Mobile phone networks complying with the UMTS standard belong to the third generation (3G) of mobile phone networks.
In order to prominently demonstrate the environmental importance the EoL phase can play within the entire life cycle of a modern mobile phone network and to prospectively extrapolate the environmental consequences associated with the transition from the second generation $(2 G)$ to the third generation $(3 \mathrm{G})$ of mobile phone network standards the presented thesis covers the following issues extensively elaborated in four case studies:

Network analysis: including network specification and decomposition, component classification, life cycle modelling, parameterisation and network recomposition.

Life cycle modelling: including EoL phase decomposition into stages and modelling, life cycle inventory.

Scenario development: includes extreme cases such as direct landfill as well as high-tech EoL processing, but also intermediary alternatives.

Screening the environmental effects associated with the EoLtreatment of a single network component in case study 1 six EoL-scenarios were developed and exemplary applied to analyse the environmental consequences associated with the EoL-treatment of an antenna rack (Scharnhorst et al. 2005b). This basic study enabled the identification of environmentally potentially critical EoL-processes and allowed for the determination of an environmentally preferable EoL-treatment alternative. The life cycle impact assessment (LCIA) suggested that alternatives without recycling are environmentally not preferable, in particular due to effects of longterm emissions from landfills. On the other hand, too sophisticated mechanical pre-treatment prior thermal recovery of metals does not necessarily result in a reduction of the overall environmental impact.

Expanding the scope, case study 2 covered the analysis of the environmental performance of an entire GSM 900 Network (Scharnhorst et al. 2005a). Taking the most recent statistical data into account the environmental importance of the different network components was analysed. Likewise, the environmental importance of the EoL-phase was compared with the importance of the production and the use phase. By applying a value correction factor (Werner 2002) the environmental consequences of different EoL-treatment strategies were analysed. The results indicate that the use phase dominates the environmental impact categories glo- 
bal warming and resource depletion. Depending on the value correction factor, the production phase dominates in terms of human health. Independent of the value correction factor, the EoL-phase dominates the ecosystem quality category. It was found that increasing the value correction factor would result in a reduction of the production phase effects on human health but would not cause any change in the other three impact categories.

In order to get real first hand data on the behaviour of heavy metals when thermally treating electronic scrap in an experimental study samples of Printed Wiring Board Assemblies (PWBA) were incinerated at lab scale under reducing as well as under oxidising conditions (Scharnhorst et al. 2006b). Assisted by extensive thermodynamic equilibrium calculations as well as measurements with a Thermo-Gravimeter/Inductively Coupled Plasma Optical Emission Spectrometer (TG-ICP-OES) it could be shown that arsenic, cadmium and gallium were completely removed from the residual ash matrix during the incineration process. It could also be confirmed that increasing the temperature under oxidising conditions results in a decreasing volatilisation of antimony and lead. Under reducing conditions the volatility of lead and zinc increases with increasing temperature. Conversely, under the latter conditions the volatility of antimony decreases again. In essence the findings suggest that reducing conditions should be avoided when thermally treating electronic scrap. In addition, a transfer of outdated electronic equipment to e.g. developing countries should only be considered if an environmentally sound (thermal) EoL-treatment can be assured in such regions.

Based on the findings of the previous investigations in case study 3 a comprehensive LCA was performed analysing the environmental effects associated with the transition from $2 \mathrm{G}$ to $3 \mathrm{G}$ mobile phone technology and again concentrating on the EoL-phase (Scharnhorst et al. 2006a). The assessment covered network techniques complying with the GSM (GSM, GPRS $^{3}$ and EDGE ${ }^{4}$ ) and with UMTS (R'99, R'04 and R'06 ${ }^{5}$ ) standards. In terms of impact per functional unit the study showed that under present conditions GSM-networks perform environmentally better than UMTS-networks. In the future however, it is expected that the impact scores of the UMTSnetworks will significantly drop below those of the GSM-networks. In terms of absolute environmental impact, today, UMTS-networks perform slightly better compared with GSMnetworks. However, with the expected increase in UMTSsubscribers the absolute impact of the UMTS-technology will

\footnotetext{
${ }^{3}$ General Packe Radio Service.

${ }^{4}$ Enhanced Data rates for Global Evolution.

5 UMTS-standard versions: Release 1999, 2004, 2006.
}

analogously increase. The study showed also that environmentally sound EoL-treatment can contribute to significantly contribute to reduce the impact of the production phase. In essence, it is suggested to keep the transition between $2 \mathrm{G}$ and $3 \mathrm{G}$ mobile phone technology as short as possible. Furthermore, the energy intensive operation of the radio network components needs to be optimised.

In conclusion, during the research LCA was perceived as a promising and powerful tool for the analysis and interpretation of environmental effects related to products of globally highly integrated industries. One of the biggest challenges however remains the development of LCA to assist efficiently and effectively in corporate decision-making.

The thesis (Scharnhorst 2005) is available directly from the author
or at: http://library.epfl.ch/theses/?nr=3443

\section{References}

CEC (2003a): On the restriction of the use of certain hazardous substances in electrical and electronic equipment (RoHS), Directive 2002/ 95/EC. Comission of the European Parliament, Brussels

CEC (2003b): On waste electrical and electronic equipment (WEEE), Directive 2002/96/EC. Comission of the European Parliament, Brussels

GSMAssociation (2005): GSMA statistics Q3/05. GSM Association $<$ http://www.gsmworld.com/news/statistics/pdf/gsma stats_q3 $\underline{05 . \mathrm{pdf}>}$

Joerges B (1988): Large technical systems: concepts and issues. In: Mayntz R, Hughes TP (eds), The Development of Large Technical Systems. Campus Verlag, Frankfur am Main

Malmodin J, Oliv L, Bergmark P (2001): Life Cycle Assessment of Third Generation (3G) Wireless Telecommunication Systems at Ericsson. Stockholm, Sweden

Nokia (2004): Environmental Report of Nokia Corporation 2004. Nokia Group, Espoo, Finland

Scharnhorst W (2005): Life-Cycle Assessment of Mobile Telephone Networks, with Focus on the Environmental Relevance of the End-ofLife Phase. PhD thesis, Swiss Federal Institute of Technology, Lausanne, Switzerland

Scharnhorst W, Althaus H-J, Classen M, Jolliet O, Hilty LM (2005a): End Of Life treatment of second generation mobile phone networks: Strategies to reduce the environmental impact. Env Imp Ass Rev 25 (5) 540-566

Scharnhorst W, Althaus H-J, Hilty L, Jolliet O (2005b): Environmental assessment of End-of-Life treatment options for an GSM 900 antenna rack. Int J LCA OnlineFirst <DOI: http://dx.doi.org/10.1065/ $\underline{\text { lca2005.08.216> }}$

Scharnhorst W, Hilty LM, Jolliet O (2006a): Life Cycle Assessment of Second Generation (2G) and Third Generation (3G) Mobile Phone Networks. Environ Int (in press)

Scharnhorst W, Ludwig C, Wochele J, Jolliet O (2006b): Heavy metal partitioning from electronic scrap during thermal End-of-Life treatment. Sci Total Environ (submitted for revision)

Werner F (2002): Treatment of Recycling of Aluminium in LCA - Development and Evaluation of the Value-Corrected Substitution Procedure Applied on Window Frames. Research and Work Report 115/47, Eidg. Materialprüfungs- und Forschungsanstalt (EMPA), Duebendorf

\footnotetext{
Dr. Wolfram Scharnhorst is scientific collaborator at the Swiss Federal Laboratories for Materials Testing and Research (EMPA). His research field comprises life cycle assessment of electronic components, experimental analysis of heavy metal volatilisation from electronic scrap during incineration, and the implementation of life cycle assessment results into practice (life cycle management). Wolfram Scharnhorst obtained a Master in micrometeorology in 2000 at the Uppsala University (Sweden) and received his Ph.D. in environmental sciences in 2006 at the Swiss Federal Institute of Technology Lausanne (EPFL). In 2005, he was visiting scientist at the Paul Scherrer Institut (PSI) performing incineration experiments of electronic scrap at lab scale. Additionally he is reviewer for several scientific journals.
} 